\title{
NARRATIVAS DOS PIBIDIANOS DE HISTÓRIA: PROCESSOS DE EMPODERAMENTO NO CONTEXTO ESCOLAR
}

\author{
Mariseti Cristina Soares Lunckes ${ }^{1}$ \\ Rosária Helena Ruiz Nakashima² \\ Jéssica Alves de Sales ${ }^{3}$
}

\begin{abstract}
Resumo
Esta pesquisa-ação investigou as relações da Educação Básica com o Ensino Superior, no âmbito do Programa Institucional de Iniciação à Docência (Pibid) de História, em uma universidade federal do norte do Brasil. Buscou compreender os significados do Pibid nos processos de empoderamento e de aprimoramento da formação do licenciando (bolsista), do professor e de seus alunos da escola-campo. Os resultados evidenciaram que um dos mecanismos para o empoderamento dos sujeitos foi a criação de espaços para que todos esses atores pudessem se expressar com autoridade de fala. Os saberes do professor da escola-campo e do bolsista foram articulados na atuação do Pibid, almejando a produção de novos capitais cultural e pedagógico, aprimorados pela prática de quem já tem experiência em lidar com os desafios do contexto escolar e pela teoria de quem está em processo de formação, com vistas à inserção na docência.
\end{abstract}

Palavras-chave: Pibid. Formação de professores. Ensino de História.

\section{NARRATIVE OF HISTORY PIBIDIAN: EMPOWERMENT PROCESS IN SCHOOL CONTEXT}

\begin{abstract}
This action research investigated the relationship of Basic Education to Higher Education under the Programa Institucional de Iniciação à Docência (Pibid) History in a federal university of northern Brazil. We seek to understand the meanings of Pibid in empowerment processes and improving the training of licensing (scholarship), teacher of the basic school system and school-camp students. The results showed that one of the mechanisms for empowerment of the subjects was the creation of spaces when all these actors could express themselves with speaks of authority. The knowledge of the teacher-school course and the stock market were articulated in the performance of Pibid. It aims at the production of new cultural and educational capital, enhanced by the practice of those already used to dealing with the challenges of the school context and the theory of who is in the making process, with a view to inclusion in teaching.
\end{abstract}

Keywords: Pibid. Teacher training. History teaching.

\section{NARRATIVAS DE LOS PIBIDIANOS DE HISTORIA: PROCESOS DE EMPODERAMIENTO EN EL CONTEXTO ESCOLAR}

\footnotetext{
${ }^{1}$ Professora Adjunta do Curso de História da Universidade Federal do Tocantins (UFT). Docente do Mestrado Profissional em Ensino de História - PROFHISTÓRIA. Coordenadora do Pibid de História na UFT de Araguaína. Graduada em História, Mestre e Doutora em História. E-mail: <lunckes@uol.com.br>.

2 Professora Adjunta do Curso de História da Universidade Federal do Tocantins (UFT). Docente do Programa de Pós-Graduação em Estudos de Cultura e Território (PPGCult). Graduada em Pedagogia, Mestre e Doutora em Educação. E-mail: <rosaria@uft.edu.br>.

${ }^{3}$ Graduada em História pela Universidade Federal do Tocantins (UFT). E-mail: <jhes yeshua@hotmail.com>.
} 
Mariseti Cristina Soares Lunckes Rosária Helena Ruiz Nakashima Jéssica Alves de Sales

\section{Resumen}

Esta investigación-acción he buscado conocer las relaciones de la Educación Básica con la Enseñanza Superior en el ámbito del Programa Institucional de Iniciação à Docência (Pibid) de Historia, en una universidad federal del norte de Brasil. Fue una búsqueda por la comprensión de los significados del Pibid en procesos de empoderamiento y perfeccionamiento de la formación del licenciando (bolsista), del profesor y de sus alumnos de la escuela-campo. Los resultados evidenciaran que uno de los mecanismos para el empoderamiento de los sujetos ha sido la creación de espacios para que todos eses actores podrían se expresar con autoridad de habla. Los saberes del profesor de la escuela-campo y del becario fueron articulados en la actuación del Pibid, deseando la producción de nuevos capitales cultural y pedagógico, perfeccionados por la práctica de quienes ya posee experiencia en lidiar con los desafíos do contexto de la escuela y por la teoría de quienes está en proceso de formación, con el objetivo de la inserción en la docencia.

Palabras-clave: Pibid. Formación de professores. Enseñanza de Historia.

\section{INTRODUÇÃO}

O Programa Institucional de Bolsa de Iniciação à Docência (Pibid), proposto em 2007 pelo Ministério da Educação (MEC) e Coordenação de Aperfeiçoamento de Pessoal de Nível Superior (CAPES), traz contribuições para a formação inicial e continuada dos professores, considerado positivo por muitos profissionais da educação, de acordo com recentes publicações que expressam avaliações sobre o Pibid (CAPES, 2013; COSTA; FERREIRA; NEITZEL, 2013; GATTI et al., 2014).

A meta 15 do Plano Nacional de Educação - PNE (BRASIL, 2014), articulada com o artigo 61 da Lei de Diretrizes e Bases 9394/96 (BRASIL, 1996), traz considerações sobre a formação dos profissionais da educação. A estratégia 15.3 do PNE menciona a ampliação do "programa permanente de iniciação à docência a estudantes matriculados em cursos de licenciatura, a fim de aprimorar a formação de profissionais para atuar no magistério da educação básica" (BRASIL, 2014, p. 26). Nessa perspectiva, ao pensar em políticas de Educação Superior e para onde caminha a universidade, é possível visualizar o Pibid como um dos territórios férteis para a construção de aprendizagens e novas experiências docentes.

O Pibid tem o objetivo de aprimorar a formação inicial de professores, contribuindo com a valorização da docência, ao mesmo tempo em que colabora com o aperfeiçoamento da Educação Básica através da união do saber teórico do ensino superior e das práticas pedagógicas autênticas, vivenciadas nas escolas. O Pibid atua como ponte entre a Universidade e a educação escolar, apoiado pela concessão de bolsas a acadêmicos de 
licenciatura de Instituições de Educação Superior (IES), que desenvolvem projetos e ações formativas em escolas-campo, sob a supervisão de um professor-regente da Educação Básica e um professor da IES.

No âmbito do Pibid de História de uma universidade federal do norte do país, no período de 2011 a 2014, professores-regentes de História da escola-campo, dez licenciandosbolsistas e um professor da IES dividiram saberes para criar soluções aos problemas educacionais vivenciados na escola-campo. Nesse processo, questionamentos foram surgindo como, por exemplo: O que significa ser bolsista do Pibid? Qual a importância da prática dos registros na formação do professor? Quais as contribuições desse Programa para a universidade e a escola-campo, onde o Pibid atua? O que é ser professor de História na atualidade?

A fim de responder tais indagações, foi realizada uma pesquisa-ação que, de acordo com Tripp (2005, p. 445), é "uma estratégia para o desenvolvimento de professores e pesquisadores de modo que eles possam utilizar suas pesquisas para aprimorar seu ensino e, em decorrência, o aprendizado de seus alunos". As pesquisadoras-autoras deste trabalho viram no Pibid a possibilidade de planejar ações de formação inicial de professores; implementá-las na escola-campo; descrevê-las em produções científicas e avaliá-las continuamente, a fim de aprimorar suas práticas de ensino, bem como a dos licenciandosbolsistas e dos professores-regentes da escola-campo.

Nesta pesquisa houve a possibilidade de integrar diferentes instâncias como, por exemplo, a direção e a coordenação pedagógica da escola; os professores-regentes; os estudantes da Educação Básica; os licenciandos-bolsistas; a coordenação do Pibid na IES e o colegiado do curso do qual o Programa faz parte. Nessa perspectiva, esta investigação tornouse uma pesquisa-ação emancipatória (TRIPP, 2005), que almejou operacionalizar mudanças em todas as instâncias envolvidas.

As discussões efetivadas durantes as reuniões pedagógicas da equipe do Pibid (professor-orientador da IES, supervisor da escola-campo e licenciandos-bolsistas), a produção de diários de campo e a sistematização dos relatórios trimestrais e finais foram as principais fontes de dados analisadas nesta investigação. 


\section{ESCOLA-CAMPO: ESPAÇO DE TROCAS DE EXPERIÊNCIAS E SABERES}

Bourdieu (2007) conceitua habitus como aquilo que se forma no indivíduo quando este se socializa com determinado grupo, em termos de reflexão e apreensão de valores. Sua manutenção está atrelada à exteriorização da cultura incorporada, como algo que vai além do indivíduo e que é ressignificado pelos grupos com que mantém contato. Trata-se de um conjunto de percepções, comportamentos e reflexões que provocam a inculcação de valores, de acordo com a posição que ocupa no campo. O campo, por sua vez, é onde o habitus se movimenta, é um espaço social com regras e hierarquias próprias, mas que, apesar de sua dinâmica determinada e determinante, recebe influências dos sujeitos que dele fazem parte.

A escola é campo de poder, "um dos instrumentos mais eficazes de integração 'moral' das sociedades diferenciadas" (BOURDIEU, 2007, p. 206). A escola possui "força formadora de hábitos" (BOURDIEU, 2007, p. 211), ao influenciar os sujeitos que se encontram direta ou indiretamente submetidos a ela, funcionando como inculcadora dos interesses da classe dominante, na medida em que o currículo é voltado para a uniformização social dos indivíduos. Assim, impondo o enquadramento do aluno nos valores da cultura dominante, através da ação pedagógica e de elementos próprios do funcionamento da escola, esta submete o aluno a uma luta constante pelo abandono de seu capital natural (aquele que advém de sua própria cultura, fora do âmbito escolar) e a interiorização do habitus da cultura dominante.

O pibidiano ${ }^{4}$ traz consigo o habitus da universidade. É o sujeito que transita entre dois campos distintos: a universidade e a escola. Na escola, ele busca conhecer sua realidade; aprende seus mecanismos de ensino, metodologias e práticas; analisa seu Projeto PolíticoPedagógico para entender seu funcionamento e seus objetivos; participa de reuniões de planejamento; observa as aulas e desenvolve ações pedagógicas. O pibidiano é um sujeito em formação, que está construindo sua base teórica na universidade, e que reconhece que a escola é um campo fértil e autêntico para a construção dos saberes necessários à prática educativa (FREIRE, 1996). A escola funcionou, para o bolsista, como um laboratório, e seu

\footnotetext{
${ }^{4}$ Neste contexto, pibidiano é o nome utilizado pelos bolsistas para se autonomearem. É comum o termo ser utilizado em publicações feitas por outros bolsistas PIBID, o que pode ser verificado nos livros publicados por bolsistas de outras áreas e de outras instituições.
} 
objeto de pesquisa foi a sua própria formação, como se vê no Relatório Anual do bolsista $A$ (2012, p. 12):

[...] todas as leituras e atividades desenvolvidas foram indispensáveis e contribuirão de maneira positiva para minha vida acadêmica. Desta forma, utilizarei estes aperfeiçoamentos no desenvolvimento dos próprios trabalhos do PIBID, como os diários de campo, os relatórios, os artigos, os relatos de vivencia etc. Este aperfeiçoamento será útil na contribuição para publicação de trabalhos dentro e fora do Programa e pode refletir também em um melhor desempenho no curso. Além disso, estas são práticas que certamente serão utilizadas por toda nossa carreira profissional.

Ao realizar as atividades pedagógicas dentro da escola, em conjunto com os estudantes e professores-regentes da educação básica (escola-campo), houve troca constante de símbolos, de valores, afeições e percepções, apoiada pela valorização de todos os saberes construídos por esses sujeitos. Houve a "consciência do inacabamento" (FREIRE, 1996, p. 55), necessária para ensinar e aprender, ou seja, o reconhecimento de que professor e estudante não se reduzem à condição de objeto um do outro, portanto, "quem ensina aprende ao ensinar e quem aprende ensina ao aprender (FREIRE, 1996, p. 25).

As contribuições foram bilaterais, tanto da equipe do Pibid, na forma de teorias, metodologias, didáticas, de novos conhecimentos e modos de ensinar, quanto da escolacampo, que aceitou que o projeto fosse desenvolvido dentro de seus muros, na forma de laboratório de aprendizagem, onde o bolsista vivenciou o que a universidade nem sempre consegue proporcionar, em relação à prática real de ensino.

Os projetos desenvolvidos dentro da escola-campo ganharam êxito quando os estudantes da referida escola passaram a participar ativamente das atividades propostas pelos pibidianos. Não é apenas a identidade do bolsista que foi construída na relação com o aluno, também a do aluno, na sua percepção de sujeito ativo na construção do conhecimento.

Percebo também que a postura dos alunos com relação a nós bolsistas mudou muito do início dos trabalhos até os dias de hoje. Hoje em dia eles nos aceitam mais como professoras deles do que como intrusos no ambiente escolar. Isso se deve ao fato de que no início os alunos nos enxergavam muito como estagiarias que viriam a escola apenas dar umas aulas durante alguns dias e depois iriam embora sem mudar nada na vida deles. O que eles mesmos desconstruíram aos perceber que nós participaríamos ativamente do cotidiano deles na sala de aula durante muito tempo e que realmente 
Mariseti Cristina Soares Lunckes

Rosária Helena Ruiz Nakashima Jéssica Alves de Sales

teríamos algo a mais para contribuir para com eles. E isso fez toda a diferença para eles, pois os mesmos relataram que nossa presença contribuiu muita na melhoria da qualidade das aulas de história. (Bolsista B, Diário de Campo, 29 de agosto de 2013).

Com a chegada do Pibid na escola-campo, os computadores e espaços de leitura ganharam vida, ao tornarem-se parte dos planos de aula dos bolsistas. O datashow para exposição de imagens e vídeos foi usado com maior frequência nas aulas. Os livros da biblioteca e os computadores passaram a ser utilizados junto ao livro didático, para auxiliar na abordagem de temas variados, e assim as aulas tornaram-se mais significativas, pois aliaram o conteúdo da disciplina ao contexto, ao conhecimento tecnológico, à reflexão e ao desenvolvimento das habilidades de escrita e de leitura.

A biblioteca, os laboratórios de informática, o convívio com sujeitos formados e em formação, a participação em eventos locais, regionais e nacionais que discutiram a educação atual, na região e no país, alimentaram o capital cultural do pibidiano, colocando-o em posição privilegiada no campo escolar, juntamente com a dos professores-regentes, que também se beneficiaram dessa troca cultural e pedagógica.

O Pibid contribuiu para a formação contínua do professor-regente, promovendo a autorreflexão de sua prática enquanto a exerce, também dando-lhe a oportunidade de participar de eventos acadêmicos, de realizar leituras, reflexões teóricas e produções de novas metodologias e recursos, e no convívio diário com a universidade, ampliando sua percepção estética do espaço escolar e melhorando sua autoestima frente às inovações do saber.

Em um processo de reflexão-ação-reflexão (práxis), as trocas culturais e pedagógicas nutriram a formação de todas as instâncias: direção e coordenação pedagógica da escola; professores-regentes; estudantes da Educação Básica; comunidade escolar; pibidianos; coordenação do Pibid e professores da IES, que também reconheceram a necessidade de fazer uma revisão de suas práticas pedagógicas para atender as demandas trazidas da Educação Básica.

O empoderamento dos sujeitos foi fruto da consciência de seu papel na construção do conhecimento emancipador e, consequentemente, as barreiras simbólicas entre Ensino Superior e Ensino Básico foram sendo rompidas, desconstruindo a ideia de superioridade da universidade sobre a escola. Em outras palavras, todos passaram a trabalhar 
para o mesmo fim, e aperfeiçoaram-se mutuamente para a formação de cidadãos críticos, capazes de refletir e intervir no seu contexto.

\section{MEMÓRIAS E NARRATIVAS NA CONSTRUÇÃO DOS SUJEITOS}

Os relatórios foram frutos dos exercícios de relatar, problematizar e criticar, em diários de campo, as ações desenvolvidas pelos pibidianos dentro da escola-campo ou do campus universitário. Nos próprios relatórios, eles reconheceram sua importância no aperfeiçoamento de suas técnicas de leitura e escrita, e mais, de reflexão da prática, pois seu processo de produção consistiu nas seguintes etapas: escrita do relatório narrando suas experiências na escola-campo, e os pontos positivos e negativos, de acordo com sua percepção e sugestões para aprimorar o desempenho do Programa dentro da escola. Em seguida, este mesmo relatório foi apresentado, discutido e corrigido para/por toda a equipe do Pibid, retornando ao autor para reformulação. Para Foucault (1986, p. 114), um discurso pressupõe outro, assim como pressupõe o que ele provocará, ou seja, "não há enunciado que não suponha outros; não há nenhum que não tenha, em torno de si, um campo de coexistências".

À luz das ideias de Bourdieu (2007), foi observado que as narrativas dos diários de campo carregaram, em si, valores e simbolismos que evidenciaram a visão crítica dos pibidianos sobre como o Programa foi tratado institucionalmente. Diferente de Foucault, é pelo viés da luta de classes que Bourdieu trata o poder simbólico das palavras e das ações. A narrativa a seguir expressa como o bolsista $C$ vem construindo sua visão sobre a realidade do Pibid, isto é, sob o seu ponto de vista, os interesses dos futuros professores não estão sendo defendidos a contento, contribuindo para possíveis fragmentações na construção do habitus docente.

Apesar das falhas do Programa em nível estadual, bem como a falta de assistência, incentivo e financiamento para a apresentação de trabalhos e participação em eventos, o PIBID da área de História do campus universitário tem se destacado pelo compromisso dos bolsistas, da coordenadora e da supervisora em cumprir com as cláusulas do edital (Bolsista C, Relatório Anual 2013, p. 5-6). 
De acordo com Freire (1996, p. 34), "ensinar exige criticidade", e o desenvolvimento desse saber docente foi valorizado pela supervisora do Pibid na IES, no processo de construção dos diários de campo e relatórios, espaços onde os pibidianos registraram os desafios vivenciados no cotidiano escolar. A maioria deles fez referência à falta de interesse dos estudantes da escola-campo pela disciplina de História; às deficiências quanto à leitura e escrita; à escassez de recursos tecnológicos e de espaço suficiente na escola para desenvolver novas metodologias; e à resistência dos estudantes às inovações pedagógicas inseridas nos planos de aula dos bolsistas. $\mathrm{O}$ trecho do diário de campo a seguir evidencia os desafios presentes na escola-campo onde atua o bolsista D:

[...] a professora falou das dificuldades enfrentadas pela direção e corpo docente da escola no que se refere ao tratamento com os alunos que são de classe baixa e como de costume, têm suas condições educacionais influenciadas pelas necessidades financeiras e sociais enfrentadas. Falou da falta de espaço no âmbito escolar para a realização de atividades importantes, necessárias. Mostrou também as taxas de reprovação, aprovação e evasão escolares, ficando clara a necessidade de melhorias no ensino (Bolsista D, Diário de Campo, 16 de agosto de 2011).

O coordenador pedagógico da escola-campo expressou que muitos acadêmicos "saem da universidade sonhando a sala de aula perfeita e sofrem o choque de perceber a contradição" (Bolsista D, Diário de Campo, 24 de agosto de 2011). A coordenação e os professores-regentes concordaram com o distanciamento entre a escola e a universidade, destacando que o diferencial do aluno que participa do Pibid é a possibilidade de instrumentalizar-se, tanto pela teoria, quanto pela prática vivenciada no ensino público.

A narrativa de uma primeira experiência em sala de aula foi: "Destacam-se, claramente, os gritos do professor e a algazarra dos alunos. O ventilador ligado faz barulho e desligado faz calor" (Bolsista E, Diário de Campo, 20 de setembro de 2011). Durante a discussão com a equipe do Pibid, foi identificado que a inexperiência em lidar com todas as limitações inerentes ao espaço escolar fez com que a bolsista E percebesse, com maior incidência, os pontos negativos da estrutura da escola. Experiências como essas foram vivenciadas por outros e, durante as reuniões com a equipe do Pibid, ficou evidente o fato de que "aprender é uma aventura criadora" (Freire, 1996, p. 77), pois foram criados espaços para 
que todos identificassem os desafios reais da escola-campo e pensassem em como superálos.

Nesse constante ir e vir de teorias e experimentos, a reflexão da prática foi fomentada e o bolsista gradualmente construiu as habilidades necessárias para o exercício da docência, e aprimorou sua formação ao problematizar as situações da realidade escolar, conforme demonstra a narrativa a seguir:

Começando pelos diários de campo, devo esclarecer que a elaboração dos mesmos não é um exercício complexo quando encarado apenas como um hábito de registrar o feito. No entanto, essa prática de escrever sobre as atividades desenvolvidas significa mais do que muitos podem imaginar, haja vista que incita a autorreflexão e, consequentemente, a autocrítica; fato que além de ser bastante complicado exige grande rigor subjetivo por parte do indivíduo. Portanto, acredito que o trabalho com os diários de campo tem contribuído no cultivo do espírito crítico e reflexivo em todos os bolsistas (Bolsista F, Relatório Anual 2012, p. 6).

A característica fundamental da escrita dos diários de campo e dos relatórios foi a possibilidade de criticar-se, de se conhecer. Lançando sobre a sala de aula da escola-campo um olhar de laboratório através dos registros, o bolsista colocou não só os estudantes e demais sujeitos da instituição em análise, mas a si mesmo. Os diferentes registros cumpriram a função de autoanálise, fazendo o bolsista olhar para sua prática e criticá-la, buscando suas lacunas e, no decorrer das atividades, observando em si mesmo os resultados do Programa em sua formação.

Além disso, o bolsista tem seus próprios saberes, um repertório teórico e metodológico atualizado que foi adquirido não apenas no decorrer da licenciatura, mas que se aperfeiçoou nas discussões provocadas no Pibid. O bolsista participou de eventos, produziu artigos, recursos didáticos e foi constantemente envolvido em projetos ligados à educação, tanto na escola-campo quanto na universidade.

Em nossa vida acadêmica como estudantes de Licenciatura em História, estas atividades tiveram relevância no sentido de subsidiar-nos no aumento de notas, principalmente, no que diz respeito às disciplinas de cunhos pedagógicos, como por exemplo: Estágio Supervisionado em História, Didática, Política, Organização e Legislação da Educação Básica etc. Gradualmente, isso pode estar refletir em um melhor desempenho no curso (Bolsista G, Relatório Trimestral 2011, p. 5). 
a) integração entre teoria e prática e aproximação $O$ bolsista $G$ atesta sua percepção de que as experiências proporcionadas pelo Programa exerceram influência em sua formação no processo de assimilação do conhecimento requerido pelas disciplinas pedagógicas, isto é, a assimilação da teoria foi propiciada a partir do exercício articulado com a prática, através do Pibid. Portanto, a grande preocupação desta pesquisa foi entender como ocorre o aprimoramento da formação do bolsista na teia de relações construídas na prática, em um contexto escolar autêntico.

Os registros efetivados pelos bolsistas contribuíram para o processo de empoderamento, pois foi possível vivenciar a experiência de fazer uma avaliação diagnóstica da escola-campo; estudar teorias e buscar práticas que contribuíssem para atender as demandas contextuais; colocar em prática o que foi planejado e avaliar os êxitos e fragilidades para as próximas ações. Além disso, o que foi percebido a partir dos diários de campo e relatórios é que os impactos positivos do Pibid, reconhecidos pela CAPES, em outros contextos, também estão sendo vivenciados nesta investigação, a saber:

entre universidades e escolas públicas de Educação Básica;

b) formação mais contextualizada e comprometida com o alcance de resultados educacionais;

c) reconhecimento de um novo status para as licenciaturas na comunidade acadêmica e elevação da auto-estima [sic] dos futuros professores e dos docentes envolvidos nos programas;

d) melhoria no desempenho escolar dos alunos envolvidos;

e) articulação entre ensino, pesquisa e extensão;

f) aumento da produção de jogos didáticos, apostilas, objetos de aprendizagem e outros produtos educacionais;

g) inserção de novas linguagens e tecnologias da informação e da comunicação na formação de professores;

h) participação crescente de bolsistas de iniciação em eventos científicos e acadêmicos no país e no exterior (CAPES, 2013, p. 8).

O Pibid não adentra à escola-campo com o objetivo de melhorar o ensino público, pelo menos não diretamente, pois seu objetivo maior é a formação do bolsista como futuro professor. Todavia, as diretrizes do programa possibilitam um potencial transformador, tanto para a Universidade, que forma o futuro professor, como para a escola-campo, como espaço de renovação, ao acolher o Pibid, e de expor seus fazeres e saberes, resignificando e atualizando-os mesmos na medida em que os resultados educacionais positivos ganham 
visibilidade. Na próxima seção serão discutidas as contribuições do Pibid para a formação da práxis educativa do futuro professor de História.

\section{PIBID: ESPAÇO DE FORMAÇÃO INICIAL DO PROFESSOR DE HISTÓRIA}

O Pibid tem sido uma importante política pública brasileira, voltada para a formação e valorização da profissão docente, evidenciando a função social da universidade em planejar e desenvolver práticas políticas e pedagógicas exitosas. Vaillant (2006 apud ANDRÉ; BARRETO; GATTI, 2011, p. 17), ao investigar as políticas docentes, identificou alguns pontos convergentes no contexto latino-americano, a saber:

- Um entorno profissional que dificulta reter os bons professores na docência. Há poucos estímulos para que a profissão seja a primeira opção na carreira. Acrescente-se a isso condições de trabalho inadequadas, problemas sérios na remuneração e na carreira.

- Muitos professores estão muito mal preparados, o que requer esforço massivo de formação em serviço.

- A gestão institucional e a avaliação dos docentes, em geral, não têm atuado como mecanismo básico de melhoria dos sistemas educativos.

Para a autora, "a formação inicial deve merecer atenção especial nas políticas docentes, porque é o primeiro ponto de acesso ao desenvolvimento profissional contínuo e tem um papel fundamental na qualidade dos docentes que passam por esse processo" (VAILLANT 2006 apud ANDRÉ; BARRETO; GATTI, 2011, p. 18). O Pibid tem se fortalecido como política de formação inicial docente, intervindo política e pedagogicamente em realidades concretas, tais como as salas de aula da Escola Básica e da universidade. Nos relatórios dos bolsistas foram registradas as evidências dessas intervenções, frutos do processo de reflexãoação-reflexão (práxis), apoiado por professores-regentes experientes da Educação Básica e Superior.

Nesses relatórios foram encontrados, por exemplo, registros sobre o desinteresse dos estudantes da escola-campo pela disciplina de História, alegando que a maioria dos alunos não entendia a necessidade de estudar História, sendo apenas um conteúdo sem função e significado. Os estudantes da escola-campo não percebiam que os conteúdos estudados poderiam instrumentalizá-los para a leitura crítica do mundo, ou seja, não reconheciam que todo o saber histórico tem relação com a vida prática. Como expectadores de narrativas 
históricas do passado, sem significado, os estudantes da escola-campo deixavam de apreender a beleza e o sentido das aulas de História e os professores tornaram-se responsáveis por "um papel mais decisivo na construção de um novo paradigma civilizatório" (GADOTTI, 2003, p. 6).

Bittencourt (2004) escreve que o estudo de História em sala de aula, na maioria dos currículos, implica em formar um cidadão crítico, capaz de transformar sua realidade, de contribuir com as mudanças e melhoria da vida em sociedade. Nesta investigação, isso significou dar vez e voz aos estudantes da escola-campo, isto é, valorizar a sua cultura, fruto de sua vivência fora da escola (a realidade de seu bairro, de sua cidade, de sua família), ampliando os seus horizontes, em um processo de empoderamento cultural, social, histórico e político.

De acordo com Pinsky e Pinsky (2004, p. 20), é papel do professor "estabelecer uma articulação entre o patrimônio cultural da humanidade e o universo cultural do aluno". Este pressuposto conduziu a pesquisa e o planejamento dos pibidianos em busca de metodologias de ensino para a aprendizagem significativa dos conteúdos presentes na proposta curricular da escola. O resultado foi a articulação dos três pilares da universidade, em outras palavras, no Pibid os bolsistas vivenciaram o ensino e a pesquisa, tento como objeto de estudo a extensão da IES, a escola-campo.

Assim, articulações se realizaram e o que se preconiza na Universidade ganhou visibilidade e concretude na Educação Básica, conforme as evidências expressas no relato abaixo:

Esse intercâmbio gerado entre a Educação Básica e a Superior é um ato que incita reações - em sua maioria positivas - e insere o estudante num processo de discussão em torno destes objetivos, inserindo-o assim neste processo de aprendizagem, tanto por parte de nós, bolsistas, quanto por parte da unidade escolar. Abordar essa questão suscitou em nós, enquanto graduandos e pesquisadores, o fato de que à comunidade acadêmica, seus gestores, dirigentes universitários, docentes e pesquisadores, cumpre o papel de seguir honrando os compromissos assumidos com a população, visando a promoção de uma educação para a paz, respeito aos direitos humanos, justiça social, multiculturalidade e promoção das minorias e dos excluídos (Bolsista H, Relatório Semestral 2013, p. 6-7). 
Durante a formação no Pibid, os bolsistas compreenderam a importância do planejamento do ensino como um processo integrador entre a escola e o contexto social (LOPES, 2005). Assim, as ações planejadas, juntamente com os professores-regentes da escola-campo, partiram da avaliação diagnóstica de cada turma; da definição dos objetivos voltados à produção do conhecimento; da seleção de conteúdos significativos e essenciais, utilizando como critério elementos da realidade histórico-social dos estudantes; da pesquisa de metodologias que provocassem reflexão, curiosidade, investigação e criatividade das turmas e da avaliação concebida com um eixo transversal, desenvolvida continuamente, visando à construção de novos conhecimentos. A vivência desse processo contribuiu para que o pibidiano compreendesse que, da experiência cotidiana da pesquisa, depende o ensinar e o aprender de processos investigativos e da inter-relação teoria e prática (BITTENCOURT, 2004), favorecendo a formação de futuros professores-pesquisadores. Esta experiência de pesquisa e ensino fez parte do trabalho no Programa, como demonstra o bolsista I:

A coordenadora [...] propôs ao grupo em uma das reuniões, uma atividade de trabalho com charges. Onde a temática [...] estava no ensino do conteúdo de história medieval, e cada pibidiano deveria construir sua sequência de charges elaborar um tema, e produzir um texto crítico sobre a aplicação dessa nova metodologia de ensino. Ao meu ver foi uma experiência muito proveitosa e bem divertida. Proveitosa porquê mostra que o educador/educando deve sempre buscar novas formas metodológicas e que saiam da rotina comum da tríade cadeira/silêncio/leitura, pois assim perderiam, nas salas de aula, um sentimento de obrigação e tedio. Abrindo lugar para um aprendizado bem mais prazeroso (Bolsista I, Relatório Anual 2013, p. 4).

A partir das colocações acima, percebe-se que o bolsista I apropriou-se das aprendizagens vivenciadas na graduação, em relação ao processo de construção e elaboração de estratégias para um ensino de História significativo. Habilidades didáticas foram experimentadas e um fazer histórico voltado para o ensino e para a pesquisa na Educação Básica foram problematizados. Elementos do saber histórico e pedagógico foram imprescindíveis na formação dos bolsistas, para que a transposição didática de conteúdos trabalhados na universidade fossem realizados na sala de aula.

A História, como construção dinâmica, foi percebida por quem ensina e aprende, pois o processo de ensino e de aprendizagem não esteve presente apenas nos conteúdos 
(imagens, representações e narrativas) que implicam em valores de diferentes sociedades no tempo. A consciência do tempo histórico no presente pressupôs ver o mundo em diferentes nuances, que só possível através da reflexão.

Assim, os conteúdos curriculares foram problematizados pelos pibidianos em palestras, produção de jornal-mural, oficinas pedagógicas com metodologias dinâmicas de ensino, pesquisa e recursos didáticos existentes na escola. A proposta do Pibid de História envolveu todos sujeitos do contexto escolar no processo de empoderamento, ao perceberem a atualidade de fatos cronologicamente remotos; a historicidade de conceitos como democracia, cidadania, liberdade, beleza, religião, sexualidade; ou seja, identificar quais as mudanças ocorridas sobre diferentes temas ao longo do tempo; ao reconhecerem preconceitos e, principalmente compreenderem seus mecanismos de atuação para poderem criticá-los com argumentos sólidos; ao compreenderem os usos e abusos da História, perpetrados por grupos políticos, nações e faç̧ões, e ao criticarem aos dogmatismos e verdades absolutas com base no reconhecimento da historicidade de situações e formas de pensamento (PINSKY; PINSKY, 2004).

As colocações dos autores evidenciam a importância de um ensino de História problematizado, pois todo conteúdo trabalhado em sala de aula só ganha significado quando o professor o submete aos questionamentos contextualizados, em diferentes tempos, espaços e com diferentes sujeitos, conforme relata o bolsista C:

Penso que que nesse sentido, o PIBID oferece um leque de possibilidades no que se refere à formação inicial, uma vez que cria oportunidades da vivência da prática docente, fazendo com que a partir dessas práticas, nós bolsistas, comecemos a fazer o constante exercício de uma reflexão crítica de nossas próprias ações. Portanto, é válido afirmar que as atividades propostas para este ano foram executadas com êxito (Bolsista C, Diário de Campo, 10 de dezembro de 2013).

Para Pinsky e Pinsky (2004, p. 28), “o verdadeiro potencial transformador da História é a oportunidade que ela oferece de praticar a 'inclusão histórica'" (grifos dos autores). Nesse sentido, através de uma reflexão crítica entre a produção do conhecimento e o ensino de história, os pibidianos aprenderam a sistematizar e socializar a reflexão sobre a prática docente, investigando o contexto educativo e analisando a prática de outros 
profissionais da educação. Os bolsistas foram inseridos na prática docente, ou seja, estão atuando na Educação Básica pública, fazendo a diferença e sendo reconhecidos como futuros professores atuantes e competentes. Em contrapartida, os estudantes da escola-campo aprenderam a gostar da disciplina de História, que passa a ter função e significado, e os professores-regentes também se beneficiaram com a vivência de novas possibilidade de ensinar e aprender História.

\section{CONSIDERAÇÕES FINAIS}

Esta pesquisa-ação emancipatória evidenciou avanços e desafios que continuarão a ser investigados com todos as instâncias da escola-campo e da universidade. Durante as reuniões e nos registros das memórias e narrativas dos pibidianos, foram pontuados os benefícios do Programa como, por exemplo, a formação do futuro professor para trabalhar com os recursos disponíveis; a relevância do planejamento e de sua avaliação; a criatividade como mecanismo necessário para superar os desafios; o papel do trabalho cooperativo para o desenvolvimento educacional e a importância da teoria para a construção da prática e viceversa.

As preocupações dos bolsistas em torno das problemáticas do ensino (estrutura física escolar precária, falta de espaço, deficiências em leitura e escrita) são angústias de sujeitos que estão conhecendo seu futuro campo de trabalho e, no mais, representam para eles desafios a serem ultrapassados para a conquista de seu lugar no campo em que estão inseridos.

O perfil dos bolsistas do Programa foi de alunos de classe $C$, que optaram pelas licenciaturas por falta de opções, devido à dificuldade financeira em se manterem em outros cursos, mas que, ao participarem do Pibid, mudaram suas percepções quanto às licenciaturas e, em sua maioria, terminaram o curso com notas altas e estão indo para as salas de aula como professores. Isso se deve ao fato de os bolsistas terem sido instigados a superarem os desafios e preparados para a realização de uma educação transformadora.

Nesta investigação, um do mecanismos para o empoderamento dos sujeitos foi a criação de espaços para que todos pudessem se expressar com autoridade de fala. Os saberes do professor da escola-campo e do bolsista andaram juntos na atuação do Pibid, almejando a 
produção de novos capitais cultural e pedagógico, aprimorados pela prática de quem já está acostumado a lidar com os percalços da vida docente e pela teoria de quem está em pleno processo de formação. Enquanto os bolsistas teceram seus planos de aula para colocar em prática o aprendizado acadêmico, expuseram seu capital cultural e este passou a ser interiorizado de forma direta e indireta pelos sujeitos do campo escolar. Isto ocorreu à medida em que se conscientizaram da oportunidade ofertada pelo Pibid para aperfeiçoarem sua prática, em uma troca constante de valores, teorias, princípios, conceitos, metodologias e atitudes.

O Pibid, mais que uma política estatal, é um programa que dá voz à sala de aula e ao seu professor, e isto se concretizou na escrita dos diários de campo, que levaram à universidade os desafios reais da escola, bem como na produção dos relatórios, que certificaram que os problemas analisados dentro da escola estão sendo trabalhados, em busca de superá-los.

Mas, para onde caminha a universidade? Nesta investigação observou-se que a universidade caminha para a compreensão de que a teoria e a prática, de mãos dadas, ganham sentido através da relação entre os sujeitos em espaços de concepções, reflexões e reformulações constantes e necessárias aos processos de empoderamento, de ensino e de aprendizagem, tanto na Educação Básica como no Ensino Superior.

\section{REFERÊNCIAS}

ANDRÉ, M. E. de A.; BARRetTo, E. S. de S.; GATTI, B. A. Políticas Docentes no Brasil: um estado da arte. Brasília: UNESCO, 2011.

BITTENCOURT, C. M. F. Ensino de História: fundamentos e métodos. São Paulo, Cortez, 204.

BOURDIEU, P. Economia das Trocas Simbólicas. São Paulo, Perspectiva, 2007.

BRASIL. LDB (1996). Lei de Diretrizes e Bases no 9.394, de 20 de dezembro de 1996.

Disponível em: <http://www.planalto.gov.br/ccivil_03/LEIS/I9394.htm>. Acesso em: 22 abr. 2014

PNE (2014-2024). Lei no 13.005, de 25 de junho de 2014. Aprova o Plano Nacional de Educação - PNE e dá outras providências. Disponível em:

<http://www.planalto.gov.br/ccivil 03/Ato2011-2014/2014/Lei/L13005.htm>. Acesso em: 20 mar. 2015. 
CAPES. 2013. Relatório de Gestão Pibid 2013. Disponível em:

<https://www.capes.gov.br/images/stories/download/bolsas/1892014-relatorio-PIBID.pdf>. Acesso em 23 jul. 2015.

COSTA, D; FERREIRA, V. S. ; NEITZEL, A. A. Os impactos do PIBID nas licenciaturas e na

Educação Básica. Conjectura: Filos. Educ, 18 (n. especial), 2013, p. 98-121.

FOUCAULT, M. A Arqueologia do Saber. Rio de Janeiro, Forense Universitária, 1986.

FREIRE, P. Pedagogia da Autonomia: saberes necessários à prática educativa. $6^{\mathrm{a}}$ ed., Rio de Janeiro, Paz e Terra, 1996, 165 p.

GADOTTI, M. Boniteza de um sonho: ensinar-e-aprender com sentido. São Paulo, GRUBHAS 2003.

GATTI, B.; ANDRÉ. M. E. D. A.; GIMENES, N. A. S. ; FERRAGUT, Laurizete (Orgs.). Um estudo avaliativo do Programa Institucional de Bolsa de Iniciação à Docência (Pibid). São Paulo, FCC/SEP, 2014,120 p.

LOPES, A. O. Planejamento do ensino numa perspectiva crítica de educação. In. VEIGA, I. P. A. (Coord.). Repensando a Didática. 22.ed. Campinas-SP: Papirus, 2005. p. 55-64.

PINSKY, J.; PINSKY, C. B. Por uma História prazerosa e consequente. In: KARNAL, Leandro (Org.). História na sala de aula: conceitos, práticas e propostas. $2^{\mathrm{a}}$ ed., São Paulo, Contexto, 2004, p. 17-36.

TRIPP, D. Pesquisa-ação: uma introdução metodológica. 2005. Disponível em: <http://www.scielo.br/pdf/ep/v31n3/a09v31n3.pdf>. Acesso em: 22 jul0. 2015.

RECEBIDO EM 21 DE JULHO DE 2015.

APROVADO EM 03 DE AGOSTO DE 2016. 